\title{
Selected Human Resources Factors as Determinants of Performance Management Framework Implementation in Kenya
}

\author{
Jane Sang ${ }^{1}$, Michael Korir ${ }^{1} \&$ Bob Wishitemi ${ }^{1}$ \\ ${ }^{1}$ Moi University, Kenya \\ Correspondence: Jane Sang, Moi University, Kenya. E-mail: cjsang@yahoo.com
}

Received: June 14, 2016

Accepted: July 6, 2016

Online Published: August 10, 2016

doi:10.5539/ijbm.v11n9p192

URL: http://dx.doi.org/10.5539/ijbm.v11n9p192

\begin{abstract}
The purpose of this paper is to examine human resource factors on implementation of performance management framework in Kenya and, specifically, at Moi Teaching and Referral Hospital (MTRH). The theory of planned behaviour and the Balanced Score Card Model were used to show how people are linked to the success of the organization. This study adopted an explanatory design that used an in depth investigation of an Institution in form of case study which was undertaken at MTRH Eldoret. The target population was all the staff of MTRH, who numbered 2,040, but a sample of each department was selected, totalling 510 respondents through simple random and stratified sampling techniques out of which 505(99\%) subjects responded. The study utilized questionnaires for data collection. Data collected was analyzed using descriptive and inferential statistical tools. Specifically Manova analysis, Correlation analysis, Factor analysis and SEMPATH model, with the help of SPSS /Amos model programme, were used to validate and test the hypotheses. Results of hypothesis testing indicate that employee attitude and leadership style have a significant relationship with implementation of performance management. The first model showed that leadership style was found not to likely affect implementation with other variable at the standardized regression measured .01 and was not significant at $\mathrm{p}>.05$. This was supported by a strong correlation between leadership and attitude at .85 as compared with .37 with implementation of performance management. A second model was therefore tested whereby leadership style were conceptualized to influence attitude and in retrospect attitude affect implementation of performance management. The standardized regression between attitude and performance management directly was .41. The study established that leadership style influence attitude which, in turn, determine employee relationship with the implementation of performance management framework. It was therefore recommended that, to effectively manage the implementation of performance framework, an organization should put in place: the right strategies which can position the organization well and allow all the concerned parties execute their duties to great heights.
\end{abstract}

Keywords: employees' attitudes, leadership style, performance management framework

\section{Introduction}

Performance management system is crucial to both employees and employers. It is important for the employers to be aware of employees' contribution to the organization goals and objectives (Mustafa, 2013). Therefore by understanding and managing a good performance management system, it can be means of getting better outcome from the organization. Performance Management is concern for everyone not just managers in the organization (Armstrong \& Baron, 2009). The introduction of human resource management is a strategic driver and plays an integrated role in performance management system (Edward, 2003). Human resource factors are part of the strategy that contribute to organization performance.

A well managed human resource factors in organisations can enhance implementation of performance management (Bowen \& Ostroff, 2004). Research has shown that HRM can play an important role in organisational performance (Boselie \& Dietz, 2003; Boselie, Dietz, \& Boon, 2005; Guest, Michie, Conway, \& Sheehan, 2003). Although a positive relationship is sometimes shown between HRM and organisational performance, little is yet known about its determinants of performance management framework (Bowen \& Ostroff, 2004; Klein \& Kozlowski, 2000).

\subsection{Problem Formulation}

The need to remain competitive, productive and open to the challenges of the future in the face of organizational 
change is becoming more important than ever (Kaplan \& Norton, 1996). Public sector reforms have become common phenomena around the globe and especially in developing countries. The Government of Kenya, therefore, started implementing Public Sector Reforms in 1993 with the aim of improving service delivery. Public Services in many African countries are confronted with many challenges which constrain their delivery capacities. The reason behind poor performance includes human resource factor(s). In light of this, the Government of Kenya embraced the policy of Public Sector Reforms. While there was a reduction of the core civil service by about $30 \%$, it was noted that Productivity and Performance in the Public Service was not as expected. The Government of Kenya, therefore, undertook the implementation of Performance Contracting since the other reforms seemed to have recorded minimal success. It is worth examining the success of implementation of performance contracting in the Public Sector. This would help establish the efficacy of Public Sector Reforms in Kenya and hence the need for this study. The question therefore is, "Is Performance Management really working for MTRH?" Scanty information is available.

The specific objectives were:

1. To assess the extent to which Employees' Attitudes on Strategies Employed affect implementation of a Performance Management Framework.

\section{To assess the Impact of Leadership Style on the Adoption of a Performance Management Framework.}

\section{Theoretical Approach of Performance Management}

The European Foundation for Quality Management's (EFQM) model indicates that good HR leadership leads to customer satisfaction, people satisfaction and impact on society. Good leadership create HRM practices leading to excellence in business results. Organizations who adopt the EFQM model, such as ICL, the Post office and KLM-Dutch Royal Airline, accept the importance of performance measurement and work all the time to improve the usefulness of their measures, but they also recognize that simply measuring a problem does not improve the quality of work.

The 360 degree feedback has been defined by Ward as "the systemic collection and feedback of performance data on an individual or group derived from a number of the stakeholders on their performance" (Armstrong \& Baron, 2009, p. 2). It is also referred to as multi-source assessment or multi-rater feedback.

The Balanced Scorecard is a model that gives a balanced presentation of both financial and operational measures. The main concern is customer perspective, internal perspective, innovation and learning and financial perspective. The organizations' strategies are aligned to the individual strategies through the Balanced Scorecard's holistic approach to performance. Kaplan and Norton (1996) devised what they call the balanced scorecard: a set of measures that gives the top management a fast but comprehensive view of the business (Armstrong \& Baron, 2009, p. 275). The The balanced scorecard communicates a holistic model that links individual efforts and accomplishments to business unit objectives.

\subsection{Leadership Theories}

There are various theories associated with leadership style. These include trait theories, behavioural theories, contingency theories, leader-member exchange theory and decision theory. This study narrowed on contingency theories (Fiedler Model and Situational Leadership Theory)

The first comprehensive contingency model for leadership was developed by Fred Fiedler. The Fiedler contingency model proposes that effective group performance depends on the proper match between the leader's style and the degree to which the situation gives control to the leader. A more recent conceptualization by Fiedler focuses on the role of stress as a form of situational unfavourableness and how a leader's intelligence and experience influenced his or her reaction to stress Fielder and associates found that a leader's intellectual abilities correlate positively with performance under low stress but negatively under high stress. And, conversely a leader's experience correlates negatively with performance under low stress but positively under high stress. It is therefore the level of stress in the situation that determines whether an individual's intelligence or experience will contribute to leadership performance (Robbins \& Judge, 2008).

\subsection{Literature Review}

\subsubsection{Employee Attitude Concept}

In a performance management, employee attitudes toward the system are strongly linked to satisfaction with the system. According to Boswell and Boudreau (2000), perceptions of fairness of the system are an important aspect that contributes to its effectiveness. Understanding employee attitudes about the performance management in organizations is important as they can determine its effectiveness (McDawall \& Fletcher, 2004). 
If the performance management is seen and believed to be biased, irrelevant or political, that may be a source of dissatisfaction with the system. Employee reaction to the performance management is a critical aspect of the acceptance and effectiveness of the system. Extreme dissatisfaction and perceptions of unfairness and inequality in the ratings may lead to the failure of the system (Murphy \& Cleveland, 1995). The criteria that must be met in order to make the system be perceived by ratees to be fair include having a formal system of appraisal, ratees must have a very high degree of job knowledge, the rates must have an opportunity to appeal against their performance ratings, the dimensions of performance must be relevant, and having action plans to deal with any weaknesses. The organizational climate must be cooperative rather than competitive (Murphy \& Cleveland, 1995). It's not only the ratees' attitudes towards the performance management that is critical. Even the attitudes of the raters are also critical to the system (Brown et al., 2010). The attitudes and approach the raters to the process have been shown to influence the quality of the appraisals. Some raters have indicated that they are reluctant to conduct the appraisals saying that they hated conducting appraisals, 'second only to firing employees'.

Recent literature reviews have confirmed that most research studies report a significant association between human resources management and performance (Boselie Dietz \& Boon, 2005; Combs et al., 2004; Wright et al., 2005). However, a research carried out by Guest, D. E and Conway, (2009) titled 'Human Resource Management, Employee Attitudes, and Workplace Performance', suggested that there is an association between an aggregated measure of HRM and work performance but they fail to show any mediating effects of employee attitude for which the current study would wish to fill the gap. In this study, the impact of employees' attitude on the implementation of a performance management framework was examined.

$\mathrm{HO}_{\mathrm{I}}$ : Employee Attitude has no significant influence on implementation of a Performance Management Framework.

\subsubsection{Leadership Styles}

The role of leadership has also been found to be relevant in employee willingness to voice ideas aimed at improving the organization and the way in which it functions (Detert \& Burris, 2007). Examples of leadership style which are current are transformational and transactional leadership. Recent research on leadership as carried out by Vaccaro et al. (2010) titled 'Management Innovation and Leadership', concluded that transformational leadership is conducive to pursuing management innovative and transactional leadership do contribute to lowering potential barriers associated with management innovative. Transformational leadership is aimed at the followers' identification with its purpose and common goals. It stimulates employees to attain to organizational goals by appealing to high-level needs for self-actualization (Bass, 1985; Burns, 1978; Lindebaum \& Cartwright, 2010). Transformational leadership consists of four dimensions: (1) idealized influence; (2) inspirational motivation; (3) intellectual stimulation; and (4) individual consideration (Avolio et al., 1999). Idealized influence represents the degree to which leaders are admired, respected, and trusted. This dimension includes charismatic behaviour that causes followers to identify with the leader and fosters a sense of intrinsic motivation to achieve goals. Inspirational motivation provides meaning and challenge to their followers, fostering team spirit and encouraging them to envision attractive future states. Intellectual stimulation prompts followers to question assumptions and be creative. Transformational leaders ensure that creativity and innovation is part of the problem solving processes. Individualized consideration includes the extent to which followers' potential is developed by attending to their individual needs, as well as creating learning opportunities and a supportive environment for growth (Bass et al., 2003).

Transactional leadership consists of two dimensions: contingent reward and active management by exception (Den Hartog et al., 1997). Contingent reward entails the clarification and specification of what is expected of organizational members and the assessment of goals and subsequent reward for its accomplishment. Through contingent reward, leaders build commitment to the fulfilment of 'contracts' with followers (Avolio et al., 1999; Bass \& Avolio, 1993). While the establishment of such contracts has been argued to hamper creativity and result in less initiatives to address new ways of facing work (Amabile, 1996, 1998), we maintain that the impact of contingent reward on management innovation can be positive (Elenkov \& Manev, 2005). This may be the case through, for instance, an increased sense of fairness and justice in the workplace in which unmet standards and objectives do not go unnoticed, while success is dutifully rewarded (Podsakoff et al., 2006; Walumbwa et al., 2008). Furthermore, active management by exception, on the other hand, involves the leader's active involvement and intervention to monitor and rectify any divergence from an agreed standard in the follower's work. Such involvement underscores the way in which change agents, i.e. leaders, can drive the process of management innovation within the organization. Other research include those carried out by Wooten \& James, 2008 titled Linking Crisis Management and Leadership competences whereby they concluded that executives 
who enable their organizations to recover from a crisis exhibit a complex set of competencies in crisis: signal detection, preparation and preparation and preventing, damage control and containment, business recovery and reflection and learning.

$\mathrm{HO}_{2}$ : Leadership style has no significant relationship with the effective implementation of a Performance Management Framework.

\subsection{Conceptual Framework}

The literature reviewed, especially on the Balanced Scorecard and the theory of planned behaviour, indicated the need to include non-financial attributes to organizational performance. The study conceived employee attitudes, organizational strategies, leadership style, and communication processes as stimulants of implementation of performance management. The independent variables include employee attitudes and leadership style.

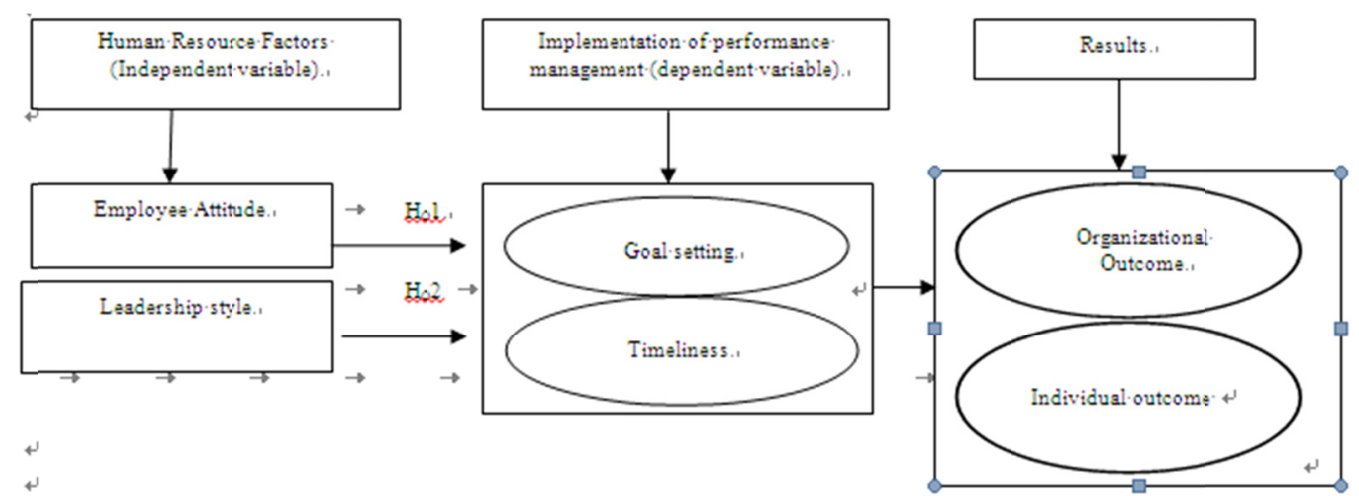

Figure 1. Conceptual framework on impact of human resource factors on implementation of performance management

Source: Author's Construct (2011).

\section{Materials and Methods}

An explanatory design was used wherein an in depth investigation of MTRH in form of case study was undertaken (Oso \& Onen, 2008). The research targeted the population of MTRH, drawing the research subjects on all cadres of staff. The staff population was 2,040 in number. The target population were the staffs who have been involved in a performance management framework. In this study, the population was divided into the different departments, specifically administration and clinical services. The study, therefore, had a sample of 510 The researcher distributed questionnaires to 510 subjects, which is a $25 \%$ representation of the staff population at MTRH. The number was chosen on the basis that this is a case study (Kothari, 2004). Primary data was used to get the necessary information through structured questionnaires. Factor analysis was also carried out to test reliability and the Cronbach Alpha was over 0.8 which was an indication that the underlying variables were testing the latent variables. Factor analysis was carried out and a composite reliability of alpha above 0.5 with total variance explained in most of the variables being above $70 \%$ which confirms the theory of above $50 \%$ (Heir et al., 2006). Discriminant validity, on the other hand, is the extent to which a construct is different from others. The validity was ensured through a measure of the promax method of rotation in factor analysis. Structural equation modelling, which allows interpretation in the face of multicollinearity, and testing of coefficient across and between multiple subject groups and models with multiple dependents ensured numerological validity test was checked (Brown, 2008). The predictive validity dimension is demonstrated by the results of the hypothesis testing.

\subsection{Data Processing, Analysis and Presentation}

The following subsections give some in-depth explanation, assumptions and justification of each of the method of analysis and their application in this study. Analytical tools such as frequency distribution, percentage and measure of central tendency were used in the study to summarise the overview and the characteristics of the respondents. The results depicted a clearer picture and general impression of the variable (Saunders et al., 2003). Factor analysis was also employed to describe variability among observed variable in terms of a potentially lower number of unobserved variables called factors. Multicollinearity was tested to show if there was any problem. A Kaiser Meyer Olkin (KMO) test, which measures sampling adequacy, (factorability of R) was also 
carried out alongside the Bartle test of sphericity, which measures the same thing as KMO in a different way. Kline (2005) recommends a sample size of more than 100, a view supported by Heir et al. (2006. Product-moment correlation coefficient (Pearson's correlation coefficient) was used to establish the degree of relationships between dependent and independent variables and as a precursor to Structural Equation Modelling.

\subsection{Structural Equation Modelling and Path Analysis}

SEMPATH is a family of multivariate statistical analytic tool that seeks to explain the relationship among multiple variables (Cooper \& Schindler, 2001; Heir et al., 2006; Kline, 2005). The hypotheses under study were fourfold: employee attitude has no significant influence on implementation of performance management and leadership style has no significant relationship with effective implementation of performance management. Each of these objectives was analysed using structural equation modelling (SEM), which was undertaken using the Amos Statistical Program (version 18).

Structural equation modelling was chosen in preference to the traditional regression procedure for the following reasons. In order to accomplish the objectives of SEMPATH analysis, three fundamental steps were followed. There is a wide disagreement among researchers on just what fit statistics to report and their level of significance. The regression weight, also called a path coefficient $(\mathrm{P})$, coefficient or a beta weight, is similar to $\mathrm{a} b$ or beta coefficient in ordinary linear regression and is similarly calculated. The $\mathrm{R}$ square measures how much variability in the dependent variable the predictors account for. The Root Means Square Residue (RMSR) and Root Mean Square Error of Approximation (RMSEA) were recently developed to replace $\chi^{2}$ statistic GOF index which has been criticized for being an unstable measure (Heir et al., 2006).

\section{Analysis and Findings}

In this section, the study presents the results from interpreted and analyzed data which include Descriptive analysis on questions answering the implementation of performance management, employee attitude and leadership style. Factor analysis and reliability analysis results on dependent and independent variables were presented and Tests on research hypotheses

\subsection{Sample Characteristics}

Gender distribution shows that there were more female respondents $(\mathrm{n}-267,52.9 \%)$ as there were male $(\mathrm{n}=238$, $47.1 \%$ ). The current age of the respondents ranged from 20 to 50 years with a majority of them aged mid to late thirties. The cadre of staff showed that majority fall under middle level followed by lower level and then senior level. Most of the staff are holders of either college certificate or university graduate which in total make $83.2 \%$ of the respondent. Majority of the staff have worked between one year to 10 years as shown the various categories of the respondent's biographical information were related with each other

\subsection{Implementation of Performance Management}

Findings indicated that implementation of performance management was above average as shown from table 1 with all practices of performance management indicting a high score which was above average. Table 1 shows the descriptive statistics for the variables assessing implementation of performance management.

Table 1. Descriptive statistics for the variables assessing implementation of performance management

\begin{tabular}{llllll}
\hline Variable $(\mathrm{n}=505)$ & Mean & Mode & S.D & Skew & Kurtosis \\
\hline 1. Customer care & 3.39 & 4 & .855 & -1.42 & 1.32 \\
2. Quality & 3.2 & 4 & .896 & -.932 & .036 \\
3. Flexibility & 3.04 & 3 & .949 & -.782 & -.282 \\
4. Competence & 3.09 & 3 & .900 & -.790 & -.136 \\
5. Skills/learning targets & 2.9 & 3 & .837 & -.593 & -.044 \\
6. Working relationships & 2.84 & 3 & .829 & -.171 & -.688 \\
7. Team contribution & 3.03 & 3 & .913 & -.647 & -.434 \\
8. Productivity & 3.13 & 3 & .894 & -.891 & .101 \\
9. Align personal objectives with organizational goals & 2.73 & 3 & .844 & -.237 & -.523 \\
10. Achievement of objectives & 2.82 & 3 & .910 & -.537 & -.421 \\
\hline
\end{tabular}

\subsection{Descriptive Results on Employee Attitude}

Vroom shows the balance between force, expectancy and valence. It is further noted that mental model or the 
unseen (attitude) in someone can move the world. Table 2 shows the descriptive statistics for the variables conceptualized to measure employee attitude. A majority of respondents stated that they were familiar with the mission statement, followed by the view that they know job requirements, and agree with the mission statement. However, sizeable proportions of the respondents disagreed or have no opinion with the notions that there was an open and comfortable work environment, training is provided and management recognized and used the skills and abilities of their workers.

Table 2. Variables conceptualized to measure employee attitude

\begin{tabular}{llllll}
\hline $\begin{array}{l}\text { Variable } \\
(\mathrm{n}=505)\end{array}$ & Mean & Mode & S.D & Skew & Kurtosis \\
\hline 1. Ready access to information & & & & & \\
2. Know mission statement & 3.38 & 4 & 1.32 & -.523 & -1.03 \\
3. Agree with mission statement & 2.63 & 4 & 1.25 & -.82 & -.48 \\
4. Involved in decision making & 3.56 & 4 & 1.31 & -.75 & -.67 \\
5. Open work environment & 3.34 & 4 & 1.34 & -.45 & -1.10 \\
6. Know job requirements & 3.32 & 4 & 1.31 & -.39 & -1.11 \\
7. Received training & 3.59 & 4 & 1.29 & -.76 & -.67 \\
8. Training provided & 3.50 & 4 & 1.32 & -.60 & -.91 \\
9. Mgm recognizes and uses my skills & 3.33 & 4 & 1.29 & -.53 & -.99 \\
10. Treated with respect & 3.32 & 4 & 1.31 & -.39 & -1.10 \\
11. Encouraged to develop new ways & 3.33 & 4 & 1.32 & -.45 & -1.06 \\
\hline
\end{tabular}

\subsection{Descriptive Results on Leadership Style}

Leadership is about influence on people you work with in a positive way. Strategy has close association with leadership and setting strategy is one of the responsibilities of leaders. Thus performance management being one of the strategies to be executed in the public sector then leadership style being employed is paramount. Respondents were divided as to whether promotion is fair or whether yearly increments are pegged on performance outcomes. However, most respondents agreed that they work with colleagues as a team, followed by working in a conducive environment and setting with superiors' yearly goals. However, a substantial proportion of the respondents are likely to disagree that turnover rate in the organisation is low. Table 3 shows the descriptive statistics for the variables measuring leadership style.

Table 3. Variables measuring leadership style

\begin{tabular}{|c|c|c|c|c|c|}
\hline $\begin{array}{l}\text { Variable } \\
(\mathrm{n}=505)\end{array}$ & Mean & Mode & S.D & Skew & Kurtosis \\
\hline 1. Turnover is low & 3.07 & 4 & 1.41 & -.18 & -1.4 \\
\hline 2. Excellent performers recognized & 3.19 & 4 & 1.19 & -.26 & -1.34 \\
\hline 3. Work in conducive environment & 3.44 & 4 & 3.44 & -.45 & -1.05 \\
\hline 4. Team work & 3.65 & 4 & 3.65 & -.69 & -.64 \\
\hline 5. Set with superiors goals & 3.36 & 4 & 3.36 & -.25 & -1.08 \\
\hline 6. Discuss with superiors my reviews & 3.25 & 4 & 3.25 & -.24 & -1.13 \\
\hline 7. Fair promotion & 3 & 4 & 3 & -.05 & -1.13 \\
\hline 8. Increment pegged on outcomes & 3 & 2 & 3 & .001 & -1.26 \\
\hline
\end{tabular}

\subsection{Factor Analysis on Implementation of Performance Management}

As discussed on section 4, the 15 underlying variables on implementation of performance management had a determinant measure of 0.000004 (and not zero), suggesting that multicollinearity might not have been a problem. The Kaiser-Meyer-Olkin (KMO) measure of sampling adequacy (also called the Factorability of R) was 0.944: above the 0.5 threshold (Field, 2005). This indicated that there appeared to be some underlying (latent) structure among the sub variables that constituted the performance management. This conclusion was buttressed by the significant finding of the Bartlett's Test of Sphericity $\left(\chi^{2}=5874.86, \mathrm{df}=91, \mathrm{p}<0.001\right)$, which measures the same thing in a different way and this was significant at .001 . All the 15 variables were initially included in the FA. Principal components analysis was used because the primary purpose was to identify and 
compute composite scores for the factors (components) underlying implementation of performance management. Initially, three components were extracted, with the initial Eigen values showing that the first component explained $59 \%$ of the variance, the second component $9.2 \%$ and a third component $6.8 \%$ of the variance. However, study of the pattern matrix table showed that the variable 'paid bonus' showed standardized loading larger than 1 on its component, which suggested that it might have been unspecified. Thus, it was removed from the analysis. All the items had primary loadings (bivariate correlations between observed variables and the components) over 0.7 and no item had a cross loading. All the variables loading on component 1 appeared to deal with goals of performance management and was labelled as 'goal setting'. The two variables loading on the second component captured the aspect of time in performance management and it was named as 'timeliness'. The composite alpha and the one for goal setting were above the benchmark of 0.7 , which showed high reliability for the items measuring the underlying constructs. However, the alpha for timeliness although high was less than .7, which suggested that more items measuring this construct could have been included in the study.

Table 4. Factor loadings and communalities based on a principal components analysis with promax rotation for 14 items measuring implementation of performance management $(\mathrm{N}=505)$

\begin{tabular}{|c|c|c|c|}
\hline & Factor 1: Goal setting & Factor 2: Timeliness & Communality \\
\hline Superiors coach me & 0.89 & & 771 \\
\hline Organisation operate performance management & 0.888 & & 0.778 \\
\hline Supervisors collect data & 0.887 & & 0.771 \\
\hline Consulted when targets are met & 0.88 & & 0.766 \\
\hline I set goal at beginning of year & 0.88 & & 0.779 \\
\hline Defined targets for every one & 0.88 & & 0.793 \\
\hline Understand aims of performance management & 0.853 & & \\
\hline I have been trained & 0.81 & & 0.759 \\
\hline I'm recognized when I excel & 0.799 & & 0.687 \\
\hline Feel good when accomplish targets & 0.796 & & 0.604 \\
\hline Individual yearly reviews & 0.738 & & 0.584 \\
\hline My targets are smart & 0.731 & & 0.652 \\
\hline Commit most time for plan & & 0.809 & 0.588 \\
\hline Took short time to implement performance system & & 0.601 & 0.713 \\
\hline Cronbach alpha (Composite .946) & & 0.961 & 0.717 \\
\hline \multicolumn{4}{|l|}{ Total Variance Explained } \\
\hline Initial Eigen values & $\begin{array}{l}\text { Extraction Sums of } \\
\text { Loadings }\end{array}$ & $\begin{array}{l}\text { Squared } \\
\text { Rotation Sums of Sc }\end{array}$ & Rotation Sums of Squared Loadingsa \\
\hline Total & $\%$ of Variance & Cumulative $\%$ & Total \\
\hline 1 & 8.588 & 61.346 & 61.346 \\
\hline 2 & 1.374 & 9.818 & 71.163 \\
\hline
\end{tabular}

\subsection{Factor Analysis on Employee Attitude}

Responses to the 11 items measuring employee attitude were subjected to a principal component analysis using ones as prior communality estimates. Initially, the factorability of the 11 items was examined using several criteria. The determinant was .00000518 , suggesting that multicollinearity might not have been a problem among the manifest variables. The KMO was 0.952 while the Bartlett's Test of Sphericity was significant $\left(\chi^{2}=6079.7\right.$, $\mathrm{df}=56, \mathrm{p}<0.001$ ), indicating that there appeared to be some underlying (latent) structure among the sub variables. The minimum bivariate correlation between any two variables was 0.655 while the highest was 0.728 , suggesting some structure among the variables and no singularity in the data. The diagonals of the anti-image correlation matrix were all above the benchmark of 0.5, which supported the inclusion of each variable in the factor analysis. Lastly, the communalities were all above 0.3 (Table 5), which further confirmed that each variable shared some common variance with other variables. Principal components analysis extracted one factor with Eigen values accounting for $71.02 \%$ of the variance (Table 5). The one factor solution was accepted because the explained variance was very high (71\%), it made a lot of theoretical logic, all the variables highly loaded only on it, and an examination of the scree plot showed the 'levelling off' of Eigen values after one factor. 
Since only one component was extracted, the solution could not be rotated, as it was needless. The table below shows the factor loadings and the communalities of the variables.

Table 5. Factor loadings and communalities based on a principal components analysis with promax rotation for 11 items measuring employee attitude $(\mathrm{N}=505)$

\begin{tabular}{lll}
\hline Loadings & & \\
& Factor 1: Employee attitude & Communality \\
\hline Management recognizes and uses my skills & .903 & .815 \\
Encouraged to develop new ways & .894 & .799 \\
Received training & .893 & .797 \\
Treated with respect & .882 & .779 \\
Know my job requirements & .882 & .778 \\
Agree with mission statement & .862 & .743 \\
Have access to information & .860 & .740 \\
Open work environment & .859 & .738 \\
Training is provided & .855 & .730 \\
Involved in decision making & .832 & .693 \\
Familiar with mission statement & .764 & .584 \\
Cronbach alpha (Composite .966) & .966 & \\
Component & \multicolumn{2}{c}{$\%$} \\
& Extraction Sums of Squared Loadings \\
1 & Total $\%$ of Variance & Cumulative \% \\
\hline
\end{tabular}

\subsection{Factor Analysis on Leadership Style}

A principal component analysis was conducted on responses to eight Likert scale questions measuring leadership style gathered from 505 participants in the study. The determinant of 0.001 suggested that multicollinearity might not have been a problem among the manifest variables. The KMO was 0.893 while the Bartlett's Test of Sphericity was significant $\left(\chi^{2}=3742.8, \mathrm{df}=28, \mathrm{p}<0.001\right)$, which indicated that the correlation matrix of the original variables was not an identity matrix and, thus, suggesting that a factor model was appropriate. The communalities were all above 0.6 (Table 6) while the diagonals of the anti-image correlation matrix were all above 0.5 , which indicated some underlying (latent) structure among the observed variables. Finally, bivariate correlations among the 15 variables were all at least 0.3 which indicated some latent construct and none were above 0.9 , which indicated no singularity in the data. Principal components analysis extracted one factor with Eigen values accounting for $71.5 \%$ of the variance (Table 6 ). The one factor solution was accepted because they explained variance was very high (72\%), it made a lot of theoretical logic, all the variables highly loaded only on it, and an examination of the scree plot showed the 'levelling off' of Eigen values after one factor. Table 6 shows the factor loadings and the communalities of the variables.

Table 6. Factor loadings and communalities based on a principal components analysis with promax rotation for 11 items measuring leadership style $(\mathrm{N}=505)$

\begin{tabular}{|c|c|c|c|c|}
\hline \multicolumn{5}{|l|}{ Loadings } \\
\hline & & & Leadership & Communality \\
\hline \multicolumn{3}{|c|}{ Discuss with superiors my reviews } & .882 & .777 \\
\hline \multicolumn{3}{|c|}{ Fair promotion } & .868 & .753 \\
\hline \multicolumn{3}{|c|}{ Excellent performers recognized } & .860 & .740 \\
\hline \multicolumn{3}{|c|}{ Work in conducive environment } & .857 & .735 \\
\hline \multicolumn{3}{|c|}{ Increment pegged on outcomes } & .856 & .733 \\
\hline \multicolumn{3}{|c|}{ Set with superior goals } & .856 & .732 \\
\hline \multicolumn{3}{|c|}{ Team work } & .798 & .637 \\
\hline \multicolumn{3}{|c|}{ Turnover is low } & .786 & .617 \\
\hline \multicolumn{3}{|c|}{ Cronbach alpha (Composite .942) } & .942 & \\
\hline \multicolumn{2}{|c|}{ gen values } & \multicolumn{3}{|c|}{ Extraction Sums of Squared Loadings } \\
\hline$\%$ of Variance & Cumulative \% & Total & $\%$ of Variance & Cumulative \% \\
\hline 71.547 & 71.547 & 5.724 & 71.547 & 71.547 \\
\hline
\end{tabular}




\subsection{Correlations between Variables}

This study conceptualized that employee attitude and leadership could influence the implementation of performance management. The Pearson correlation coefficient ranges from 0 (if no relationship exists) to 1 (for a perfect relationship). All the six predictor variables in this study were significantly related (all had $\mathrm{p}<0.001)$ with the dependent constructs (goal setting and timeliness). The relationship between each independent variable and dependent variable are all positive. This means that the variables move together in the same direction, that is, they increase or decrease together. For example, when attitude improves, goal setting likely improves and vice versa. The results are shown in the Table 7.

Table 7. Correlations between variables

\begin{tabular}{|c|c|c|c|c|c|}
\hline $\begin{array}{l}\text { Variable } \\
(\mathrm{n}=505)\end{array}$ & & $\begin{array}{l}\text { Goal } \\
\text { setting }\end{array}$ & Timeliness & Attitude & Leadership style \\
\hline Goal setting & $\mathrm{r}$ & 1 & & & \\
\hline Timeliness & $\mathrm{r}$ & $.268^{*}$ & 1 & & \\
\hline Attitude & $\mathrm{r}$ &. $.821^{*}$ & $.160^{*}$ & 1 & \\
\hline Leadership style & $\mathrm{r}$ & $.749^{*}$ & $.257^{*}$ & $.818^{*}$ & 1 \\
\hline
\end{tabular}

$\mathrm{r}=$ Pearson correlation coefficient; $*=$ correlation significant at .01 level (2-tailed).

\subsection{Tests of Research Hypotheses}

The hypotheses under study were four-fold: employee attitude has no significant influence on implementation of performance management; strategies used by the management have no relationship with effective implementation of performance management; leadership style has no significant relationship with effective implementation of performance management and communication channels have no significant relationship with effective implementation of performance management. Each of these objectives was analysed using structural equation modelling (SEM), which was undertaken using the AMOS statistical program (Version 18).

\section{$H_{o}$ 1: Employee Attitude has no Significant Influence on Implementation of Performance Management.}

Performance management was specified as a latent endogenous variable, measured by its two indicator variables, goal setting and timeliness. Attitude was specified as an exogenous, measured variable, since it was the only component extracted from a set of variables measuring employee attitude in the questionnaire. However, path analysis of the resultant diagram showed a standardized path coefficient of $>1$ of the path running from the latent (performance management implementation) to one of indicator variable (goal setting). The associated error variance of goal setting was also negative, a non-sensical value usually called a "Heywood case" (Brown, 2008). Heywood cases are caused by several factors, such as misspecification of the model, presence of outliers in the data, small sample sizes with only two indicators per latent or population correlations close to 1 or zero (ibid). The probable causes of the Heywood case, in this instance, were the too few indicators for the latent or the high correlation between the dependent and independents. To solve this, the model was constrained by specifying a small positive value (of 0.001) for the offending error term. Normality for the variables was checked by viewing skewness and kurtosis values outputted by AMOS. Since, none of the variable had a skewness or kurtosis value outside the benchmark \pm 2.0 (the highest value for skewness and kurtosis were -1.02 and -.872 , respectively), Maximum likelihood estimation method was used in AMOS. A key assumption of this method requires the variables to be normally distributed. The final path diagram is shown in the figure below.

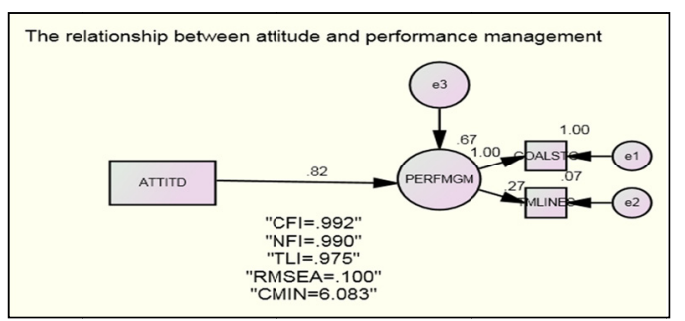

Figure 1. Output SEMPATH model on impact of employee attitude on implementation of performance management framework 
Several fit measures indicated that the overall fit of the model to the data was very good. AMOS outputs a wide array of fit measures. There is a wide disagreement among researchers on just what fit statistics to report and their levels of significance. This study, following many other studies, reported the model chi-square, RMSEA, and the baseline measures (NFI, TLI, and CFI). Since the study did not involve comparing the developed model with other models in literature, there was no need to report parsimony measures, such as parsimony normed fit index (PNFI) and parsimony comparative fit index (PCFI) and the information theory measures, such Akaike Information Criterion (AIC), Bayesian Information Criterion (BIC) and Browne-Cudeck Criterion (BCC). The model chi-square, also called discrepancy function, likelihood ratio chi-square, chi-square fit index, or chi-square goodness of fit was significant, $\mathrm{P}(\mathrm{CMIN})=6.08, \mathrm{df}=1, \mathrm{p}=.014$, suggesting that the model's covariance structure may not have been similar to the observed covariance matrix. However, considering the other goodness of fit indexes, this was discounted because the chi-square tends to be too conservative, that is, prone to Type II error.

The RMSEA (root mean square error of approximation) evaluates the extent to which a model fails to fit the data per degree of freedom. RMSEA for this model was 0.1 and its confidence interval was LO90 $=0.036$ and HI90 = 0.183 . Thus, the population RMSEA value was likely to range between the two intervals. The model likely fitted the data well as indicated by PCLOSE (Test of Close Fit) of 0.09. PCLOSE is the p value testing the null hypothesis that RMSEA is no greater than 0.05 . Since the models $p$ value was not significant $(0.09$ is $>0.05)$, the null hypothesis that RMSEA was less than 0.05 was accepted, indicating good fit. Baseline comparison measures compare the fit of a model to the independence model (the one that assumes all relationships among measured variables are zero). These measures include normed fit index (NFI), also called the Bentler-Bennett normed fit index, the Tucker-Lewis index (TLI) and the comparative fit index (CFI). Most of these measures range from 0 to 1 . These measures should be above 0.90 to indicate good model fit. In the model, NFI, TLI and CFI were $0.990,0.975$ and 0.992 , respectively, indicating that the model fitted the data well.

The table below shows the unstandardized regression weights also called structural (path) coefficients, their standard errors (SE), critical ratios (C.R), and their p values.

Table 8. Regression weights: (group number 1-default model)

\begin{tabular}{|c|c|c|c|c|c|c|c|}
\hline & & & Estimate & S.E. & C.R. & $\mathrm{P}$ & Label \\
\hline PERFMGM & $<---$ & ATTITD & 0.733 & 0.023 & 32.252 & $* * *$ & par_2 \\
\hline GOALSTG & $<---$ & PERFMGM & 1.000 & & & & \\
\hline TMLINES & $<---$ & PERFMGM & 0.236 & 0.038 & 6.230 & $* * *$ & par_1 \\
\hline
\end{tabular}

The regression weight, also called a path coefficient, $\mathrm{p}$ coefficient or a beta weight, is similar to $\mathrm{a} b$ or beta coefficient in ordinary linear regression and is similarly calculated. It also estimates the strength of the relationship between a predictor and a criterion variable by predicting the amount of change in the dependent variable for each one unit change in the independent variable. The table shows that both the regression coefficients for the model are significantly different from zero beyond the 0.01 level, as indicated by the column labelled $\mathrm{p}$. A positive coefficient means that the predicted value of the dependent variable increases when the value of the independent variable increases. The path that is critical in testing the first null hypothesis (employee attitude has no significant influence on implementation of performance management frameworks) is the one that runs from ATTITD (Attitude) to PERFMGM (performance management). Since its path coefficient is significant and positive it means that an improvement in employee attitude likely increases implementation of performance management, as measured by goal setting and timeliness. Thus, the null hypothesis that employee attitude has no influence on implementation of performance management was rejected and the alternative hypothesis that it has was accepted. The path coefficient in the model from ATTITD to PERFMGM is 0.733, which is a sample estimate of the population parameter. This indicates that when attitude increases by one unit on its scale, implementation of performance management likely improves by about $73 \%$. The critical ratios are simply the path coefficients divided by their corresponding standard errors. For example, $0.733 / 0.023=32$. A critical ratio is therefore a $t$ value that is used to test the null hypothesis that path coefficient is not significantly different from zero. At $95 \%$ confidence interval, a critical ratio that is greater than 1.96 means that the path coefficient is significantly different from zero. However, since AMOS outputs the $\mathrm{p}$ values also, the CRs are simply redundant.

The standardized regression weights (which are shown in the path diagram) are measured in standard deviation units and are therefore not dependent on the units of measurement of the variables. The advantage of the 
standard partial regression coefficients then is that their magnitudes can be compared directly to show the relative standardized strengths of the effects of several independent variables on the same dependent variable. However, since the diagram has only one independent variable, this was not necessary.

$\mathrm{R}$ square for performance management in the model was 0.67 . $\mathrm{R}$ square measures how much variability in the dependent variable the predictors account for. This means that employee attitude could explain $67 \%$ of the variation in implementation of performance management. Since $\mathrm{R}^{2}$ values above $40 \%$ are considered high, this model could therefore explain a lot of the variation in the dependent variable. In other words, we can predict, to a great degree and with more confidence that employee attitude likely influences implementation of performance management. The remaining unexplained variation in performance management could partly be attributed to other factors not specified in the model and partly to the error term (labelled e3) in the model. Recent survey indicate for example that 62 percent of UK companies employ some form of goal setting performance (Baron \& Armstrong, 2009). The current study then is contributing to the overall view of other researches whereby corporation are urged to take goal setting seriously as it is one of major attitude to employee attitude. The nation that some of the respondent felt that management do not recognize them and work environment was wanting can negate the attitude towards goal setting. Goal setting is known to raise the commitment level of all those involved in helping the organization to achieve them. MTRH and other Public Institutions have to work on Employee attitude towards goal setting in order to improve or achieve proper implementation of performance management. The correlation between goal setting and attitude at .821 is a measure that no Institution should ignore. Attitude was one of the variables most strongly related to goal setting at $82 \%$.

The factors critical to satisfactions across stakeholder groups are timeliness of communication, honesty and completeness of the information and the empathy and equity of treatment by management (Strong, Ringer, \& Taylor, 2001). The correlation coefficient between timeliness and attitude was .160. The result supports the result of strong et (Ibid). This results showed that timeliness is more related to communication than attitude though in African set-up, timeliness is not generally taken seriously and this is an area that needs to be research on more.

$H_{0}$ 2: Leadership Style has no Significant Relationship with Effective Implementation of Performance Management Framework.

As the factor analysis established, only one construct called leadership style for the variables dealing with leadership. This construct was modelled as an exogenous, manifest variable. As before, performance management was specified as a latent, endogenous variable, with two indicators, goal setting and timeliness. The variables were only slightly non-normal (the largest skewness and kurtosis values were -1.02 and -1.023 ), hence MLE method was used.

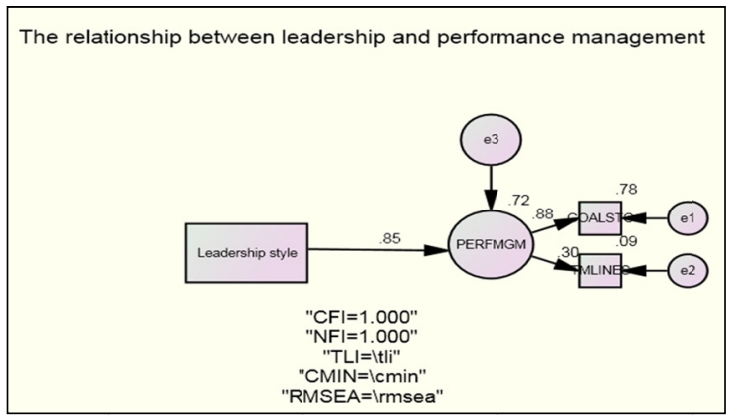

Figure 2. Output SEMPATH model on impact of leadership style on implementation of performance management framework

Source: Survey Data (2011).

Several fit measures indicated that the overall fit of the model to the data was very good. The model chi-square was not significant, $\mathrm{P}(\mathrm{CMIN})=0.000$, thus, the model's covariance structure was likely to be similar to the observed covariance matrix. However, because the model was just-identified (that is it contained the maximum number of parameters), the degrees of freedom were zero and hence, the $p$ value for CMIN could not be computed (the reason the value is not shown on the path diagram). Likewise, RMSEA and TLI could not be calculated for similar reasons. However, the values for NFI, and CFI were both 1.0, which indicated that the model fitted the data well. 
The table below shows the unstandardized regression weights, their standard errors (SE), critical ratios (C.R), and their $\mathrm{p}$ values.

Table 8. Regression weights: (group number 1-default model)

\begin{tabular}{|c|c|c|c|c|c|c|c|}
\hline & & & Estimate & S.E. & C.R. & $\mathrm{P}$ & Label \\
\hline PERFMGM & $<---$ & LDRSHP & .677 & .027 & 25.349 & $* * *$ & par_2 \\
\hline GOALSTG & $<---$ & PERFMGM & 1.000 & & & & \\
\hline TMLINES & $<---$ & PERFMGM & .303 & .051 & 5.969 & $* * *$ & par 1 \\
\hline
\end{tabular}

The path coefficient from LDRSHP (leadership) to PERFMGM (implementation of performance management was significant beyond the 0.01 level and is positive. It is also a sample estimate of the population coefficient. Thus, there is likely to be a relationship between leadership and implementation of performance management. Since the relationship is positive, it means that when leadership improves, implementation of performance management also increases and vice versa. The coefficient for leadership is .677, which means that when leadership increases by one unit on its scale, implementation of performance management increases by about $68 \%$.

Thus, the null hypothesis of no relationship between leadership and implementation of performance management was rejected. The standardized regression weight for LDRSHP to PERFMGM was 0.85 . This showed that the relationship between the variables was strong. $\mathrm{R}$ square for performance management in the model was 0.72 . Thus, leadership could explain $72 \%$ of the variation in implementation of performance management. The remaining unexplained variation in performance management could partly be attributed to other factors not specified in the model and partly to the error term (labelled e3) in the model. The results supports the notion that the role of leadership has been found to be relevant in employee willingness to voice ideas aimed at improving the organization and the way it function (Deternt \& Birris, 2007). Focus on this study will be on transformational and transactional leadership. Drawing on the wok of Burns (1978) and Bass (1985) on leadership behaviours, transformational and transactional leadership have featured in various studies in order to capture the extent to which leaders engage their subordinates by instilling in them the organization goals, or clarifying the rewards that will follow from the attainment of such goals (Rubin et al., 2005; Yammarino et al., 1997, 1998). Transformation leadership is aimed at the followers' identification with its purpose and common goals. It stimulates employees to attain to organizational goals by appealing to high-level needs for self-actualization (Bass, 1985; Burns, 1978; Lindebaum \& Cart Wright, 2010). The role of transactional leaders has also been argued to be closely related to reinforcement and refinement of institutional learning (Vera \& Crossen, 2004), which suggests that this type of leadership behaviour may be condusive to the pursuit of management innovation as it may contribute to reducing organizational complexity (Daman Pour, 1996) and ambiguity through setting clear goals and rewards that underpin underlying changes in processes, practices or structures. The current study contribute to new insights regarding influence of leadership on goal setting (implementation of performance management). Leaders are important internal actors within the organization and the kind of internal change agents (Birkinshaw et al., 2008) who impact the implementation of new practices, processes and structure. Public institutions therefore, must analyze the attributes of the leaders in various arms of the government if implementation of performance management framework is to succeed and this is the gap this study strives to fill.

\section{Conclusion and Recommendations}

This study opted for the conceptualization of two models to help concretize its findings and using these, help draw conclusions from its findings. From model one, as shown in Figure 4, the study concludes the following: Employee attitude, strategy employed, leadership style and communication are positively related to implementation of performance framework. Although leadership was found to significantly influence performance management when combined with other variable this influence was not significant.

On the other hand, from model two, the study draws the following conclusions: Organization strategy influences Employee attitude. Leadership style influences Employee attitude. Communication does to a large extent influence Employee attitude. As a consequence the three variables collectively impact on attitudes which resultantly affect performance management. In expanding the variables, it can be concluded that leadership style, communication cascading and self assessment do influence employee attitude which in retrospect affect goal setting and post results.

If appropriate leadership is in place, then good strategies will be put forward and communicated to all concerned 
without imbalance which will then trigger the attitude of the employees in a positive way leading to effective implementation of performance management framework. The conceptualized overall model supports the above view.

Secondly, the study clearly established that the more one is educated, the trickier it is to change the attitude. The female employees were seen to have understood the study questionnaire and rated highly on various variables. The relationship reveal the reverse in that male were seen to be highly rated in various hypothesis. There is need to apply different strategies to the more learned and less learned individuals while executing strategies. The lowly educated may not change jobs or employer but their understanding of new changes will be wanting.

Thirdly, this study established that there is need to include people when making changes as self assessment was strongly related to implementation of PM than 360 degree feedback. Essentially the study concluded that attitude can drain or boost the energy of an individual. The approach by the leader to the employee will dictate the results. Triggers of attitude are therefore to be executed in the right manner. Fourthly, whereas leadership has been observed by many researchers as the key driver to success of an organization, this study showed leadership as non-influential without employee attitude. Leadership then does not lead to great results without influencing employee attitude. Employee is an important asset to the organization as much as a leader as they was a strong correlation between leadership and altitude of $82 \%$.

\subsection{Recommendations}

\subsubsection{Implications and Recommendations for Managers and Organizations}

Most research has addressed performance issues in relation to financial and personnel development and smart measures. This study unearthed the need to understand human resource factors such as employee attitude and leadership styles. Different approaches will be necessary to be applied to the different cadres of staff in terms of execution of strategies and leadership. The organizations and especially public corporation then have to choose their leaders well and ensure they have good leadership qualities.

\subsubsection{Implication and Recommendation for Employees}

Employees are the most important asset to any organization. The employees have to work on their attitudes in order to succeed in their career path. The choice to perform one duty solely depends on the individual. The learned females in this research showed that they understood what they were doing and chose to not be influenced by the leadership employed. The employee has no choice but to know that change is inevitable and if not adopted then one becomes like a dinosaur.

\subsubsection{Recommendations for Further Research}

From the gaps identified in the literature review, a number of possible research opportunities arose which when explored may shed more light on the impact of human resource factor on implementation of performance management framework especially in public sector. The literature review revealed that few empirical studies have been undertaken in African context yet employee behaviour may not be the same in developed and developing countries. This should be of concern to the African government and the academic body. Therefore, a comparative study on employee behaviour would be useful. There is need for a study on the different approaches when handling employees in respect to their academic qualification. Organization should be concerned with this because this is one channel of losing talents to competition.

\section{References}

Ajzen, I., \& Fishbein M. (2002). Belief, Attitude, Intention and Behaviour: An Introduction to Theory \& Research (2nd ed.). New York: Macmillan Publishing Co.

Armstrong, M., \& Baron, A. (2009). Performance Management, a Strategic and Integrated Approach to Achieve Success. Mumbai: Jaico City Publishing House.

Armstrong, M., \& Murlis, H. (1994). Reward Management: A Handbook of Remuneration Strategy and Practice (3rd ed.). London: Kogan Page.

Atkinson, A. A., Waterhouse, J., \& Wells, R. (1997). A Stakeholder Approach to Strategy Measurement. Sloan Management Review, 25-37.

Babbiel, E. (1992). The Practice of Social Research (6th ed.). California: Wadsworth Publishing Company.

Bates, R. A., \& Holton, E. F. (1995). Computerized Performance Monitoring: A Review of Human Resource Issues. Human Resource Management Review, 267-288.

Beer, M., \& Ruh, R. A. (1976). Employee Growth through Performance Management. Harvard Business Review, 
59-66.

Brown, M. F. (2008). Challenges to Implementing Performance Management. National Performance Management Advisory Commission Paper.

Chowdhury, M. (1997). Motivating the Sales Force: The Pygmalion Effect. UMI Dissertation Service.

Cole, G. A. (2000). Organizational Behaviour. London. W12 8AW: Letts Educational Aldine Place.

Cooper, D. R., \& Schindler, P. S. (2001). Business Research Methods (7th ed.). Boston: McGraw-Hill.

Fletcher, C. (1993). Appraisal: Routes to Improved Performance. London: Institute of Personnel and Development.

Furnham, A. (2004). Performance Management Systems. European Business Journal, 16, 83-74.

Gall. M. D., Gall, J. P., \& Borg, W. R. (2003). Educational Research: An Introduction (7th ed.). Boston: Pearson Education, Inc.

Glendenning, P. M. (2002). Performance Management: Pariah or Messiah. Public Personnel Management, 31, 161-178.

Government of Kenya, Office of the Prime Minister. (2010). Performance Contracting Guidance (7th ed.). Nairobi: Government Printer.

Graham, J. (2004). Development a performance-Based Culture. Journal for Quality \& Participation, 27, 4-8.

Graziano, A., \& Raulin, M. (1997). Research Methods: A Process of Inquiry. USA: Longman.

Hartle, F. (1995). Transforming the Performance Management Process. London: Kogan Page.

Heir, J. F., Black, W. C., Babin. B. J., Anderson, R. E., \& Tatham, R. (2006). Multivariate Data Analysis (6th ed.). New Jersey: Prentice Hall.

Helm, C., Holladay, C. L., \& Tortorella, F. A. (2007). The Performance Management System: Applying and Evaluating a Pay-for-Performance Initiative. Journal of Healthcare Management, 52, 49-62.

Herzberg, F., Mausher, B., \& Snyderman, B. B. (1957). The Motivation to Work. New York: John Wiley.

Hox, J. J., \& Belhger, J. M. (2003). An Introduction to Structural Equation Modelling. Family Science Review, $11,354-373$.

Jones, P., Palmer, J., Whitehead, D., \& Needham, P. (1995). Prisms of Performance. The Ashridge Journal, $10-14$.

Kagaari, J., Munene, J. C., \& Ntayi, J. M. (2010). Performance Management Practices, Employee Attitude and Managed Performance. International Journal of Education Management, 507-530.

Kaplan, R. S., \& Norton, D. P. (1996). Using the Balanced Scorecard as a Strategic Management System. Harvard Business Review, 75-85.

Kline, R. B. (2005). Principles and Practice of Structured Equation Modelling (2nd ed.). New York: The Guildford Press.

Kobia, M., \& Mohammed, W. (2006). The Kenya Experience with Performance Contracting. Arusha: AAPAM.

Kothari, C. R. (2004). Research Methodology, Methods \& Techniques. Delhi: New Age International (P) Ltd. Publishers.

Lawson, P. (1995). Performance Management: an overview. In M. Walters (Ed.), The Performance Management Handbook. London: Institute of Personnel and Development.

Lockett, J. (1992). Effective Performance Management: A Strategic Guide to getting the best from People. London: Kogan Page.

Mugenda, O., \& Mugenda, A. (1999). Research Methods: Quantitative and Qualitative Approaches. Nairobi: Acts Press.

Oso, W. Y., \& Onen, D. (2008). A General Guide to Writing Research Proposal and Report: A Handbook for Beginning Researchers (2nd ed.). Kampala: Makerere University Printery.

Porter, M. E. (1997). Strategy. Address at the Institute of Personnel and Development's Annual Conference, Harrogate, USA.

Robson, C. (1993). Real World Research: A Resource for Social Scientists and Practitioner-Researchers. Oxford: 
Blackwell.

Saunders, M., Lewis, P., \& Thornhill, A. (2003). Research Methods for Business Students (3rd ed.). Harlow: Prentice Hall.

Sekeran, U. (2003). Research Methods for Business: A Skill Building Approach (4th ed.). New York: John-Wiley.

Stewart, L. G., \& Brown, K. G. (2009). Human Resource Management: Linking Strategy to Practice. GGS Book services.

Tabachnick, B., \& Fidell, L. S. (2007). Using Multivariate Statistics (5th ed.). Boston: Pearson Education Inc.

Trivedi, P. (2002). Performance Contracts in Kenya: Instruments for Operationalizing Good Governance. Washington: A World Bank Document.

Van De Vliet, A. (1997). The New Balancing Card. Management Today, 78-79.

Vroom, V. (1964). Work and Motivation. New York: Wiley.

Walliman, N. (2005). Your Research Project (2nd ed.). New Delhi: Vistaar Publications.

Zikmund, W. G. (2003). Business Research Methods (7th ed.). Mason: Thomson South-Western.

\section{Copyrights}

Copyright for this article is retained by the author(s), with first publication rights granted to the journal.

This is an open-access article distributed under the terms and conditions of the Creative Commons Attribution license (http://creativecommons.org/licenses/by/4.0/). 